\title{
Review
}

\section{Use of Race, Ethnicity, and National Origin in Studies Assessing Cardiovascular Risk in Women With a History of Hypertensive Disorders of Pregnancy}

\author{
Amy Johnston, MSc, CPH, ${ }^{\mathrm{a}, \mathrm{b}, \mathrm{c}}$ Victrine Tseung, PhD, ${ }^{\mathrm{c}}$ Sonia R. Dancey, ${ }^{\mathrm{d}}$

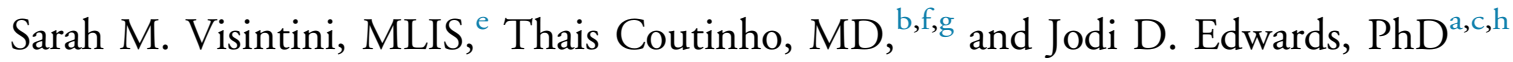 \\ a School of Epidemiology and Public Health, Faculty of Medicine, University of Ottawa, Ottawa, Ontario, Canada \\ ${ }^{b}$ Division of Cardiac Prevention and Rehabilitation, University of Ottawa Heart Institute, Ottawa, Ontario, Canada \\ ${ }^{c}$ Brain and Heart Nexus Research Program, University of Ottawa Heart Institute, Ottawa, Ontario, Canada \\ ${ }^{d}$ School of Medicine, University of Ottawa, Ottawa, Ontario, Canada \\ eBerkman Library, University of Ottawa Heart Institute, Ottawa, Ontario, Canada \\ ${ }^{f}$ Division of Cardiology, University of Ottawa Heart Institute, Ottawa, Ontario, Canada \\ ${ }^{g}$ Canadian Women's Heart Health Centre, University of Ottawa Heart Institute, Ottawa, Ontario, Canada \\ ${ }^{h}$ IC/ES, Ottawa, Ontario, Canada
}

\begin{abstract}
Women with a history of hyperBtensive disorders of pregnancy (HDP) are at particularly high risk for cardiovascular disease (CVD) and CVDrelated death, and certain racial and ethnic subpopulations are disproportionately affected by these conditions. We examined the use of race, ethnicity, and national origin in observational studies assessing CVD morbidity and mortality in women with a history of HDP. A total of 124 studies, published between 1976 and 2021, were reviewed. We found that white women were heavily overrepresented, encompassing $53 \%$ of all participants with HDP. There was limited and heterogeneous reporting of race and ethnicity information across studies and only 27 studies reported including race and/or ethnicity variables in at least 1 statistical analysis. Only 2 studies mentioned the use of these variables as a strength; several others $(k=18)$ reported a lack of diversity among participants as a study limitation. Just over half of included articles $(k=68)$ reported at least 1 sociodemographic
\end{abstract}

Cardiovascular disease (CVD) is the leading cause of hospitalization among Canadian women, ${ }^{1}$ and the leading cause of death for women worldwide. ${ }^{2}$ Women with a history of

Received for publication June 15, 2021. Accepted August 10, 2021.

Ethics Statement: The research reported has adhered to relevant ethical guidelines.

Corresponding author: Ms Amy Johnston, University of Ottawa Heart Institute, Room H-2258, 40 Ruskin Street, Ottawa, Ontario K1Y 4W7, Canada. Tel,: +1-613-620-0902.

E-mail: AJohnston@ottawaheart.ca

See page S111 for disclosure information.

\section{RÉSUMÉ}

Les femmes ayant des antécédents de troubles hypertensifs de la grossesse (THG) présentent un risque particulièrement élevé de maladies cardiovasculaires (MCV) et de décès liés à ces dernières, et certaines sous-populations raciales et ethniques sont touchées de manière disproportionnée par ces maladies. Nous avons examiné l'utilisation de la race, de l'ethnicité et de l'origine nationale dans les études observationnelles évaluant la morbidité et la mortalité liées aux MCV chez les femmes ayant des antécédents de THG. Un total de 124 études, publiées entre 1976 et 2021, ont été examinées. Nous avons constaté que les femmes blanches étaient fortement surreprésentées, puisqu'elles constituaient $53 \%$ de l'ensemble des participantes atteintes de THG. Les renseignements relatifs à la race et à l'ethnicité étaient limités et hétérogènes d'une étude à l'autre, et seules 27 études ont indiqué avoir tenu compte de variables relatives à la race ou à l'ethnicité dans au moins une analyse statistique. Seules deux études 
variable other than race and ethnicity (eg, marital status and income); however, none investigated how they might have worked synergistically or antagonistically with race and/or ethnicity to influence participants' risk of CVD. These findings highlight significant areas for improvement in cardiovascular obstetrics research, including the need for more robust and standardized methods for collecting, reporting, and using sociodemographic information. Future studies of CVD risk in women with a history of HDP should explicitly examine racial and ethnic differences and use an intersectional approach. not assessed or reported precisely enough for research needs. This is especially problematic for authors of systematic reviews (SRs) and meta-analyses, which can provide the highest level of evidence for causal association, ${ }^{9}$ as inconsistent and incomplete reporting in primary studies can lead to information about race and ethnicity becoming unusable. ${ }^{10}$ Although often used interchangeably, race and ethnicity have different meanings and are distinct social constructs. ${ }^{11-13}$ There are currently no globally accepted definitions of race and ethnicity. ${ }^{14}$ However, in general, race is used to categorize individuals on the basis of perceived physical differences, such as skin colour. ${ }^{13}$ In contrast, ethnicity refers to membership of a cultural group and may be tied to an individual's nationality, language, or religion, among other factors. ${ }^{13}$ Although these constructs are commonly reported in health research, ${ }^{11}$ they are far more subjective than an individual's age or sex, ${ }^{12}$ often resulting in their being weakly measured, poorly analyzed, and inadequately reported. ${ }^{10}$

Because the use of race and/or ethnicity can affect the quantification of cardiovascular risk estimates, it is imperative that researchers (1) carefully report on and discuss why race and ethnicity variables are used, (2) discuss how these variables are assessed, and (3) discuss the potential implications of study findings based on their use. ${ }^{15}$ Critically, others ${ }^{5,15,16}$ note the need to avoid erroneously attributing disparities in health outcomes to specific racial or ethnic groups without attempting to understand or investigate the underlying causes of disparities. To this end, a 2020 report $^{13}$ published by the Canadian Institute for Health Information outlined proposed standards for collecting race and indigenous identity data in health care, noting a lack of consensus on data collection standards for these variables. Further, as recently as March 2021, Ontario-based administrative health data provider ICES ${ }^{17}$ announced a call for participants to become members of a "People's Panel" with the goal of creating of a race and ethnicity data framework "to ensure the anti-racist use of race, ethnicity and immigration data." 18 Medical journals are also taking note of the need for more careful consideration of the terminology used when describing race and ethnicity. For example, a 2021 Journal of the American Medical Association ${ }^{19}$ editorial discussed revisions to its submission requirements on race and ethnicity and announced a formal request for input on ways to improve. ont mentionné l'utilisation de ces variables comme un point fort; plusieurs autres $(k=18)$ ont signalé un manque de diversité parmi les participantes comme une limite de l'étude. Un peu plus de la moitié des articles inclus $(k=68)$ ont fait état d'au moins une variable sociodémographique autre que la race et l'ethnicité (p. ex., l'état matrimonial et le revenu); aucun toutefois n'a étudié la manière dont ces variables auraient pu agir en synergie ou en opposition avec la race ou l'ethnicité pour influencer le risque de MCV des participantes. Ces résultats mettent en évidence des points importants à améliorer dans la recherche sur l'obstétrique cardiovasculaire, notamment la nécessité de méthodes plus fiables et normalisées en matière de collecte, de communication et d'utilisation des données sociodémographiques. Les prochaines études sur le risque de MCV chez les femmes ayant des antécédents de THG devraient examiner explicitement les différences raciales et ethniques et adopter une approche intersectionnelle.

Given recent and increasing calls for improved reporting and analysis of race and ethnicity, coupled with the serious short and long-term consequences that HDP can have on women's cardiovascular health and its increasing global prevalence $^{20,21}$ - especially among racial and ethnic subpopulations ${ }^{21,22}$ - it is prudent to examine how researchers have used race and ethnicity in studies assessing CVD risk in women with a history of HDP. To address this gap, in this rapid review, we conducted a new analysis examining the use of race, ethnicity, and national origin in prior observational studies assessing CVD morbidity and mortality in women with a history of HDP.

\section{Methods}

A rapid review is a type of evidence synthesis produced using streamlined systematic review (SR) methodology to address a predefined research question(s) and the most rigorous methods that a reduced timeframe allows. ${ }^{23-25}$ As noted by Polisena et al., ${ }^{26}$ there is no standardized approach to conduct a rapid review, as the methods used should be tailored to meet the specific needs of the study (eg, the expertise of the research team, nature of the evidence base, research question[s], and study aims) as well as those of the end user. ${ }^{27}$ Some of the more common methodologic strategies used in rapid reviews include (1) the use of recently published SRs as a starting point in identifying eligible literature, $^{28}$ (2) literature screening and inclusion by a single reviewer, ${ }^{29}$ (3) limiting the breadth of evidence synthesis to a descriptive summary/categorization of data, ${ }^{24}$ (4) narrowing study eligibility criteria (eg, including literature published in English only), ${ }^{29}$ and (5) omitting a formal risk of bias assessment or quality appraisal of included studies. ${ }^{29,30}$ Critically, in their comparison of rapid and systematic reviews addressing similar research questions, Watt et al. ${ }^{31}$ found that the conclusions of reviews conducted using either approach were similar.

\section{Review context}

This review adds novel information to previous work $^{15,32-35}$ that explored the use of race and ethnicity in epidemiologic and health services research. We build on this 
literature by focusing our exploration of these concepts within the context of studies estimating cardiovascular risk in women with a history of HDP.

\section{Eligibility criteria}

We used recently published SRs/meta-analyses to populate an initial list of potentially eligible primary studies. Full descriptions of eligibility criteria for both SRs and primary studies are provided in Supplemental Tables S1 and S2, respectively. Briefly, SRs were eligible for inclusion if authors included observational studies (ie, cohort studies, case-control studies, and cross-sectional studies) examining CV morbidity and mortality in women with a history of HDP. Specific CVDs of interest included heart failure, arrhythmias, ischemic heart disease (including coronary heart disease and myocardial infarction), stroke, and death from CV causes. In addition to these CV outcomes, SRs that included studies examining the association between HDP and chronic hypertension (HTN) were also of interest because of its robust association with CVD risk and mortality. ${ }^{36}$ Included primary studies obtained from published SRs and the literature search update (see Literature Search and Screening section) were screened for inclusion according to the inclusion criteria shown in Supplemental Table S2. Conference abstracts, letters, case reports, opinion pieces, and studies published in languages other than English were excluded. No restrictions were placed on year of publication for primary studies.

\section{Literature search and screening}

Two literature searches were designed and carried out by an experienced research librarian (S.V.) on May 20, 2021, in MEDLINE (see Supplemental Tables S3 and S4 for full search details). The first search was carried out to identify recently published SRs. The second literature search was used to identify recently published primary studies. Both searches comprised terms related to pregnancy-induced hypertensive disorders and were informed by previously conducted systematic literature searches. ${ }^{37,38}$ The first search was limited to English-language SRs or health technology assessments published from 2020 to present. $^{39}$ The second search also incorporated terms relating to coronary artery disease, heart failure, stroke, and myocardial infarction, and was limited to English-language observational studies ${ }^{40}$ published from 2019 to present. A gray literature search was not undertaken. All results were exported to Covidence (Melbourne, Australia), and duplicates were eliminated using the platform's duplicate identification feature.

Deduplicated search results were imported into DistillerSR (Ottawa, Canada), which was used to facilitate the screening and data extraction process for our race and ethnicity analysis. SRs and primary studies were managed in separate project folders. First, the titles/abstracts of all records identified through literature searches were screened for inclusion by a single author (A.J.) against the eligibility criteria. The full text of all records identified as potentially eligible based on the results of the title/abstract screen were then assessed for full eligibility. The included study lists of fully eligible SRs were then imported into EndNote (New York, NY) bibliographic software and the platform's duplicate identification feature was used to remove duplicate records. All deduplicated records were then imported into DistillerSR and the full texts screened for inclusion.

\section{Extraction of race and ethnicity data from primary studies}

All data were independently extracted by three authors (A.J., V.T., S.D.) into customized extraction forms housed in DistillerSR. Pilot tests were completed on 5 studies by all reviewers, and adjustments were made as required before full data extraction began. Two reviewers (A.J., S.D.) audited extracted data for completeness and accuracy. When necessary, disagreements were resolved by consensus.

Data extracted from fully eligible primary studies included:

- Study characteristics (author name, publication year, journal name and type, funding, country of conduct, cardiovascular outcomes reported, study design, data source, aims and objectives)

- Race, ethnicity, and geographical origin of participants (geographical origin or participants; if and where race and ethnicity were reported in the study; the terms used to describe race and ethnicity; how race and ethnicity were defined, assessed, and reported; whether and how race and ethnicity were included in analyses; and number of participants by race or ethnic category by HDP diagnosis)

- Other sociodemographic characteristics reported by authors (eg, participant income, marital status, education, employment, religious affiliation)

Study and population characteristics were only extracted if they were relevant to this review. For example, information about irrelevant exposures and comparison groups such as gestational diabetes or women with a history of normotensive pregnancies was not extracted. Further, in the event of a composite exposure (eg, maternal placental syndrome), only information about participants with HDP was extracted. If the geographic location of participants was not stated, the location of the corresponding author was extracted in its place. Supplemental material and previously published methods were not routinely collected or examined for information of interest unless authors explicitly reported that information pertinent to this review was reported elsewhere (eg, supplemental analyses by race or ethnicity or demographic information presented for the study population). Studies were considered to have included participants of a single race or ethnicity if authors made explicit statements such as "black women."

\section{Quality assessment}

In accordance with our rapid review protocol, included primary studies were not formally assessed for quality. However, given that we were interested in the reporting and use of race, ethnicity, and national origin in studies of observational design, we noted which studies made use of the Strengthening of Reporting of Observational Studies in Epidemiology $(\mathrm{STROBE})^{41}$ guideline or its extension, the Reporting of Studies Conducted Using Observational Routinely Collected Health Data (RECORD) ${ }^{42}$ statement, as appropriate. First 
published in 2007, the STROBE guidelines were created to improve the reporting quality of observational studies. ${ }^{43}$ The RECORD extension should be used for observational studies that use routinely collected health data. ${ }^{42}$ Because the STROBE guidelines were published in 2007, we only looked for the use of these guidelines in primary studies published in 2008 or later.

All included SRs from which most our primary studies were obtained were independently assessed for quality by 2 independent reviewers (V.T., S.D.) using A Measurement Tool to Assess Systematic Reviews" (AMSTAR-2). ${ }^{44}$ Discrepancies were adjudicated by a third reviewer (A.J.).

\section{Results}

We use the term women when reporting all results, as this is the term that was used in all included studies to describe study participants. We recognize that this is a gendered term that may not be generalizable to all study participants and acknowledge that not all currently or previously pregnant persons identify as women.

\section{Study selection and general characteristics}

After screening 196 records identified through literature search one, we identified a total of 6 SRs, published in $2020^{38,45-48}$ and $2021^{49}$ (Supplemental Table S5; Figure S1) from which an initial set of 174 potentially eligible primary studies were identified. A total of 524 records were obtained from our second search for recently published primary studies. After excluding records that did not meet our eligibility criteria, a total of 124 primary studies ${ }^{3,50-172}$ were included for full review (Supplemental Table S6).

All included primary studies were published between 1976 and 2021, with most studies (72\%) published in the last 10 years. Across included studies, we noted a general lack of reporting on the theoretical justification for using (or omitting) race and/or ethnicity in statistical models as well as a lack of justification for, or reflection on, the methods used to classify participants into a particular race and/or ethnicity group. Of the 103 studies published in 2008 or later, only $2^{77,171}$ reported making use of the STROBE ${ }^{77}$ or RE$\mathrm{CORD}^{171}$ reporting guidelines. Only one ${ }^{171}$ included a copy of their checklist summarizing where each item was addressed in their manuscript.

Most studies used a cohort design $(\mathrm{k}=98 ; 79.0 \%), 12$ were case-control studies $(9.7 \%)$, and 14 were of crosssectional design (11.3\%). A wide range of HDP diagnoses were reported in included studies, with more than half of participants (or HDP deliveries) having been diagnosed with PE alone or one of 15 author-reported PE subtypes. The authors of about a quarter of included studies $(\mathrm{k}=35)$ reported that HDP diagnoses were obtained using International Classification of Diseases (ICD) codes, and in 19 studies, this information was obtained from participant questionnaires (ie, self-reported obstetric history) (Supplemental Table S7).

Just over half of included studies $(k=64)$ reported on the risk or odds of HTN in women with a history of HDP. In 45 of those studies, HTN was the only reported outcome of interest. The second most commonly reported cardiovascular outcome was ischemic heart disease (including coronary heart disease and myocardial infarction), which was reported by
$30 \%$ of included studies. A similar but slightly lower proportion of studies reported on stroke $(27 \% ; \mathrm{k}=34)$ and a further 24 studies reported on CVD as a composite outcome. An additional 23 studies also reported on cardiovascular mortality. Finally, 13\% of included studies reported on heart failure, whereas only $4 \%(k=5)$ reported on risk of cardiac arrhythmia in women with a history of HDP.

\section{Geographic location of participants}

Figure 1 shows a geographic heat map of the global spread of participants represented in cardiovascular obstetrics (cardioobstetrics) research as it pertains to women with a history of HDP. Three quarters of participants with a history of HDP (including HDP deliveries) resided in the United States $(\mathrm{n}=$ $3,382,939)$. Of the remaining $1,093,303$ participants, most (81\%) were from the United Kingdom $(\mathrm{n}=363,830$; $33.3 \%)$, Denmark $(\mathrm{n}=193,331 ; 17.7 \%)$, Norway $(\mathrm{n}=$ $174,243 ; 15.9 \%)$, and Canada $(\mathrm{n}=156,082 ; 14.3 \%)$. The least well represented countries included Turkey $(n=25)$, India $(n=39)$, Kenya $(n=63)$, Chile $(n=71)$ and Brazil $(\mathrm{n}=70)$. Only one study ${ }^{138}$ involved participants residing in Africa, and no studies involved residents of northern Eurasia (eg, Russia, Tajikistan, Uzbekistan).

\section{Race and ethnicity}

Use of the terms race and/or ethnicity. The terms race and ethnicity were reported in some form (eg, ethnic, ethnicities, racial) in less than half of included studies $(k=55)$. In 15 of these studies, $53,64,69,75,93,110,118,122,132,135,141,147,157,160,171$ these terms were used interchangeably (eg, racelethnicity or race-ethnicity). In six studies, ${ }^{55,61,115,130,131,134,159}$ authors used the term ethnicity exclusively, and in 12 others, ${ }^{68,72,73,81,83,86,89,97,129,142,145,154}$ study authors only used the term race. Other related terms used to study populations included ethnically, ${ }^{102}$ racially, ${ }^{87}$ and socioeconomically diverse, ${ }^{102}$ and some participants were described as belonging to specific ancestory, ${ }^{67}$ or ethnic group(s). ${ }^{79,85,151}$

Reporting of race and/or ethnicity information. The authors of 18 included studies (15\%) explicitly reported that study participants were of a single race, ethnicity, or national origin. Specifically, 1 study each included only (South) Korean, ${ }^{100}$ Northeastern Brazilian, ${ }^{76}$ American Indian, ${ }^{62}$ Iranian, ${ }^{149}$ Norweigan, ${ }^{152}$ Dutch, ${ }^{60}$ and black ${ }^{167}$ women. Two studies each included only white or Caucasian ${ }^{60,126}$ and Finnish women, ${ }^{111,119}$ and 3 studies each included only Japanese, ${ }^{114,133,137}$ and Taiwanese $e^{103,117,158}$ women. Across the other 106 studies, a modest percentage reported any raceand ethnicity-related information (eg, as related to participant characteristics or in their introduction or discussion sections of their article). As summarized in Figure 2, since the 1970s, the average proportion of studies reporting on these sociodemographic constructs has generally increased over time from $33 \%$ of articles published from 1978 to 2001 to $67 \%$ of articles published in 2018 to 2021 (103\% change).

Of the 106 studies that did not explicitly involve participants of the same race or ethnic group, only 65 authors reported information pertaining to race or ethnicity anywhere in 


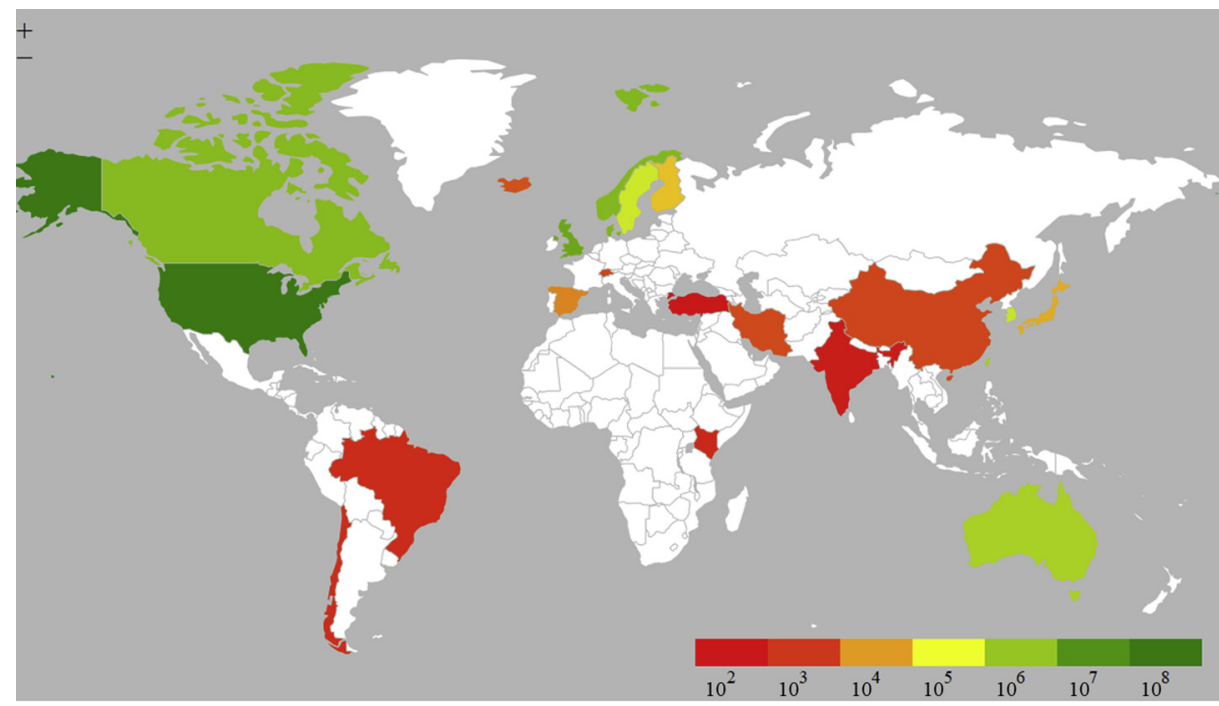

Figure 1. Geographic heat map illustrates the relative number of participants with a diagnosis of hypertensive disorders of pregnancy (HDP) in studies that assessed its association with cardiovascular morbidity and mortality. The number of participants with a history of HDP spanned 5 orders of magnitude; thus, the data are displayed on the $\log _{10}$ scale (eg, 25 is equal to $10^{1.4}$ on the $\log _{10}$ scale) to facilitate the visual comparison of these large disparities. All raw data and corresponding $\log _{10}$ values are provided in Supplemental Table S8.

their published manuscript. Nearly $68 \%(\mathrm{k}=44)$ reported on participant race and/or ethnic group in a results table (eg, participant characteristics), and only $30(46 \%)$ also discussed participant race and/or ethnicity in the results text (Table 1). Only 2 studies ${ }^{86,122}$ mentioned the use of race and/or ethnicity variables as a strength of their study; however, several more $(\mathrm{k}=18)$ reported that a lack of racial and/or ethnic diversity among study participants was a study limitation. One study completed in Canada ${ }^{115}$ discussed the use of immigration status as a proxy for ethnicity, and another study conducted in The Netherlands ${ }^{67}$ advised their study population involved a "low prevalence of immigrants."

Nearly one-third of included studies reported that participant race and/or ethnicity was assessed through participant selfreport (eg, through questionnaires), whereas just over one quarter $(\mathrm{k}=17)$ were assigned to a racial and/or ethnic category based on the use of existing records (eg, clinical registries).
Twenty-nine percent of studies $(\mathrm{k}=19)$ referred to race and/or ethnicity as demographic variables, whereas only $5^{51,69,110,101,122}$ referred to these constructs as sociodemographic variables. The authors of 4 studies $^{73,89,131,156}$ reported matching study participants based on race, and another ${ }^{79}$ reported limiting at least 1 secondary analysis to white participants with no explanation for this restriction. One 2010 study $^{135}$ presented unadjusted CVD death rates by maternal race.

Among studies that included race and/or ethnicity in at least 1 statistical analysis $(k=27)$, most $(59 \%)$ reported that these variables were adjusted for in statistical models. Only 2 studies $^{75,122}$ reported the inclusion of data on race and/or ethnicity as part of an interaction term. The authors of a recently published study ${ }^{122}$ reported excluding participants of other race/ethnicity from analysis because of low numbers. More than half of these studies (approximately $52 \%)$ reported significant findings related to race and/or

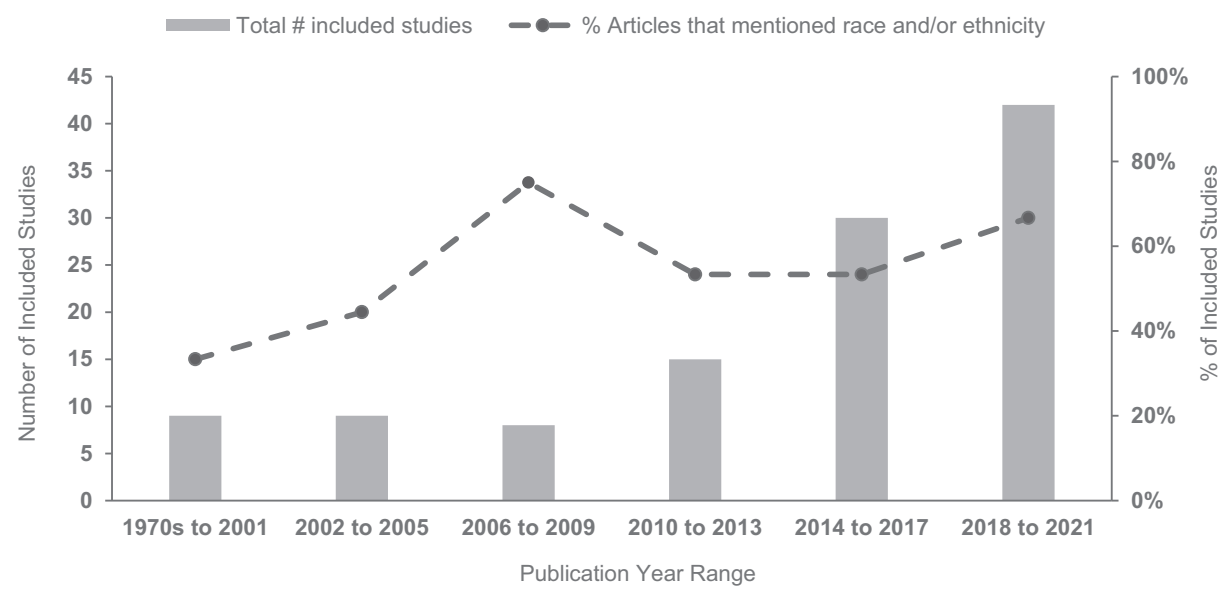

Figure 2. Number of included studies published from 1978 to 2021 in 6 publication-year categories and the corresponding percentage of studies that mentioned race and/or ethnicity in any way. 
Table 1. Use of race or ethnicity variables in studies assessing cardiovascular morbidity and mortality in women with a history of hypertensive disorders of pregnancy

\begin{tabular}{|c|c|}
\hline Use of race or ethnicity variables & $\begin{array}{l}\text { Number of studies } \\
\quad(\% \text { of total })\end{array}$ \\
\hline \multicolumn{2}{|l|}{ Position in article* } \\
\hline Introduction & $6(9.2 \%)$ \\
\hline Methods & $41(63.1 \%)$ \\
\hline Results (tables) & $44(67.7 \%)$ \\
\hline Results (text) & $30(46.2 \%)$ \\
\hline Discussion & $21(32.3 \%)$ \\
\hline Strengths & $2(3.1 \%)$ \\
\hline Limitations & $18(27.7 \%)$ \\
\hline \multicolumn{2}{|l|}{ Stated method of assessment* } \\
\hline Participant self-report & $21(32.3 \%)$ \\
\hline Existing records & $17(26.2 \%)$ \\
\hline Not stated & $9(13.8 \%)$ \\
\hline Other $^{\dagger}$ & $1(1.5 \%)$ \\
\hline \multicolumn{2}{|l|}{$\begin{array}{l}\text { Stated purpose of use or reason for } \\
\text { collection* }\end{array}$} \\
\hline Demographic variable & $19(29.2 \%)$ \\
\hline Sociodemographic variable & $5(7.7 \%)$ \\
\hline Confounder or adjustment variable & $16(24.6 \%)$ \\
\hline Not stated & $3(4.6 \%)$ \\
\hline Other ${ }^{\ddagger}$ & $2(3.1 \%)$ \\
\hline \multicolumn{2}{|l|}{ Stated method of use in analysis ${ }^{\S}$} \\
\hline Risk factor & $1(3.7 \%)$ \\
\hline Confounder & $8(29.6 \%)$ \\
\hline Interaction term & $2(7.4 \%)$ \\
\hline Covariate & $6(22.2 \%)$ \\
\hline Control for & $2(7.4 \%)$ \\
\hline Adjust for & $16(59.3 \%)$ \\
\hline Unclear & $5(18.5 \%)$ \\
\hline \multicolumn{2}{|l|}{ Reported and discussed results ${ }^{\S}$} \\
\hline Reported significant findings & $14(51.9 \%)$ \\
\hline Discussed findings & $10(37.0 \%)$ \\
\hline Called for further research & $5(18.5 \%)$ \\
\hline Not stated & $6(22.2 \%)$ \\
\hline
\end{tabular}

${ }^{*}$ Among studies that reported on race and/or ethnicity of participants and did not involve 1 race or ethnic group exclusively $(k=65)$.

${ }^{\dagger}$ One study ${ }^{85}$ assessed participant ethnicity based on father's birthplace (no rationale provided).

${ }^{\ddagger}$ One study each described race or ethnicity variables as "baseline factors" $" 102$ and information of "intrinsic interest. ${ }^{" 15}$

${ }^{\S}$ Among studies that included race and/or ethnicity in at least 1 inferential analysis (apart from descriptive analyses) $(\mathrm{k}=27)$. Note that some studies may have used more than 1 term; thus, the total is more than 27 .

ethnicity, but only 10 discussed them in detail. Five

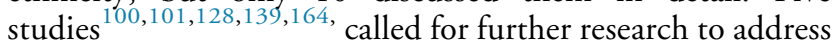
knowledge gaps related to the generalizability of findings to more diverse populations.
Reporting of participant race and ethnicity. As shown in Table 2, 61 studies (49\%) did not report on participant race and/or ethnicity. Among those that did $(\mathrm{k}=45)$, the highest number of race and/or ethnic groups reported in a single study was 7 , which was noted in 2 studies published in $2018^{132}$ and $2020 .{ }^{171}$ Two other recently published studies ${ }^{53,112}$ reported that participants belonged to 1 of 6 different race and/or ethnic groups, and 7 studies ${ }^{64,75,85,93,116,135,157}$ reported that participants belonged to 1 of 5 different race and/or ethnic groups, 5 of which ${ }^{64,75,93,116,157}$ were published in 2015 or later. The median/mean number of race and/or ethnic categories reported generally increased over time.

The range of race and ethnicity groups reported on by studies was extensive, with the highest proportion of studies reporting participants of white race (Table 3). Several studies $(\mathrm{k}=22)$ reported that participant race or ethnicity was unknown, missing, unspecified, or other, and several different terms were used to describe the same construct (eg, Caucasian, white, non-Hispanic white, European descent). Only 3 studies ${ }^{64,75,132}$ reported if participants identified as multiracial, mixed, or multiple race.

\section{Participant race and ethnicity by HDP diagnosis}

A total of 2,871,907 women with a history of any HDP (or HDP deliveries) were categorized into a race or ethnic group by study authors. More than 1.5 million participants $(53 \%)$ were described as white, Caucasian, non-Hispanic white, or European (including Finnish, Norweigan, and Dutch)-2.8 times more participants than the next highest represented race or ethnic group, Hispanic or Latino $(\mathrm{n}=544,957)$ (Figure 3). Nearly 110,000 participants with a history of HDP were classified as other, unknown or unspecified race or ethnicity, representing $4 \%$ of the total. Just over 400 participants were described as African and 35 women with HDP in included studies were Iranian.

\section{Other sociodemographic variables}

Although the primary focus of this review was on the reporting of race and/or ethnicity, we also noted other sociodemographic variables reported on by authors of included studies (see Supplemental Table S6). Briefly, just over half of included studies $(\mathrm{k}=68)$ reported on at least 1 sociodemographic variable other than race and ethnicity, such as participant marital status, socioeconomic status, religious affiliation, and type of health insurance. Of these, most authors (74\%) also explicitly reported having included 1 or more

Table 2. Number of categories of race or ethnicity reported in included studies*

\begin{tabular}{|c|c|c|c|c|}
\hline \multirow[b]{2}{*}{ Publication year } & \multirow[b]{2}{*}{ Total nNo. of studies } & \multicolumn{3}{|c|}{ No. of race and/or ethnic categories reported } \\
\hline & & Median categories & Mean categories & Minimum, maximum categories \\
\hline $1970 s-2001$ & 1 & 2 & 2 & N/A \\
\hline $2002-2005$ & 2 & 4.5 & 4.5 & 4,5 \\
\hline 2006-2009 & 4 & 1 & 1.3 & 1,2 \\
\hline $2010-2013$ & 5 & 3 & 2.8 & 1,5 \\
\hline 2014-2017 & 12 & 2.5 & 2.6 & 1,5 \\
\hline 2018-2021 & 21 & 3 & 3.5 & 1,7 \\
\hline Did not report on race and/or ethnicity & 61 & & & \\
\hline TOTAL & 106 & & & \\
\hline
\end{tabular}

${ }^{*} \mathrm{k}=124$ included studies; however, this summary table excludes $\mathrm{k}=18$ studies in which authors reported that all participants were of the same race or ethnicity. 


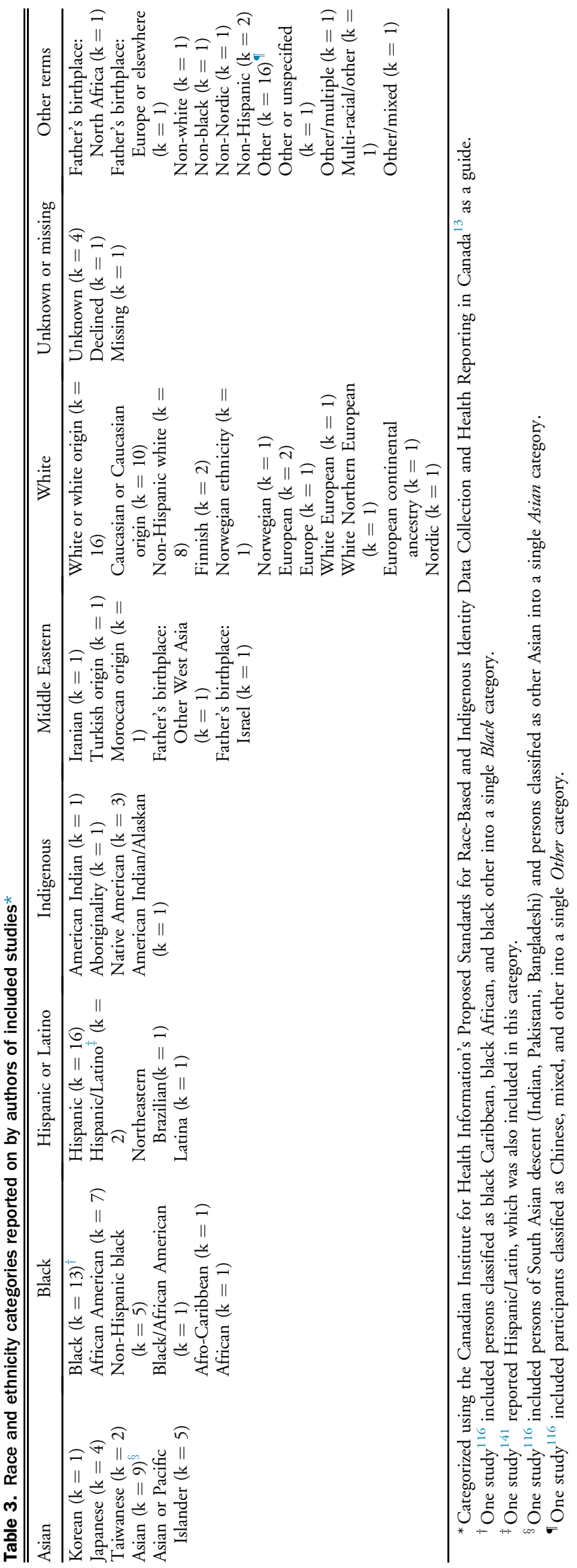

of those factors as an adjustment variable or covariate in at least 1 statistical model. These types of sociodemographic varibles varied widely across studies, both in terms of how they were defined, breadth of variables reported, and in terms of the combination of variables that were incorporated into statistical models.

The most commonly reported sociodemographic variables reported by authors were participant education and marital status. Measures of socioeconomic status and social class varied most widely, ranging from factors such as annual family income, ${ }^{135}$ employment information (ie, job title or category), ${ }^{63,125,168}$ to composite variables that derived an overall score for each participant using previously established methods (eg, the Index of Relative Socio-Economic Advantage and Disvantage ${ }^{54}$ and Nam-Powers socioeconomic scores ${ }^{159,160}$ ). These scores combined information about a variety of factors such as car ownership, neighbourhood-level social class and overcrowding, and highest level of education and occupation, among other factors. ${ }^{55,153}$ Two studies published in $1997^{94}$ and $2005^{85}$ used husband's occupation as a measure of participant social class but provided no rationale for doing so (eg, participants may not have been employed outside the home, and the tools used to assess social class did not account for this kind of work).

Only $25(20 \%)$ studies reported on participant sociodemographic information in addition to race and/or ethnicitiy; however, none investigated how the additional sociodemographic variables they collected (eg, education, marital status, income, rural vs urban setting, insurance payer) may have had synergistic or antagonistic effects with race and/ or ethnicity to influence participants' risk of CVD.

\section{Discussion}

In this review, we examined the use of race, ethnicity, and national origin in observational studies assessing CVD morbidity and mortality in women with a history of HDP. Overall, we found limited and heterogeneous reporting of race and ethnicity information across included studies. Despite evidence of substantial racial and ethnic differences in the prevalence estimates for HDP, which range from less than 3\% for Chinese and Vietnamese women to $8.9 \%$ for Indigenous American women and nearly $10 \%$ for non-Hispanic black women, ${ }^{173}$ we found that white participants were heavily overrepresented in the literature. Continents such as Africa, where the burden of HDP is high, ${ }^{22}$ exceeding $20 \%$ of all pregnancies in Botswana alone, ${ }^{1 / 4}$ were also poorly represented. Despite the burden of HDP being higher across several racial and ethnic minority groups, almost no studies examined race and/or ethnicity differences in the association between HDP and CVD outcomes.

\section{Findings in light of previous research}

The methodologic issues related to the reporting and use of race and/or ethnicity identified in this review align with those reported in several published studies. ${ }^{32-35,175,196}$ The overrepresentation of white populations in health research has been frequently observed, ${ }^{34,35,176,177,178}$ and others ${ }^{179}$ have noted it as a major limitation of studies examining cardiovascular risk in women with a history of HPD. Like others, ${ }^{35}$ we found limited reporting of race and ethnicity information 


\section{Any Hypertensive Disorder of Pregnancy}
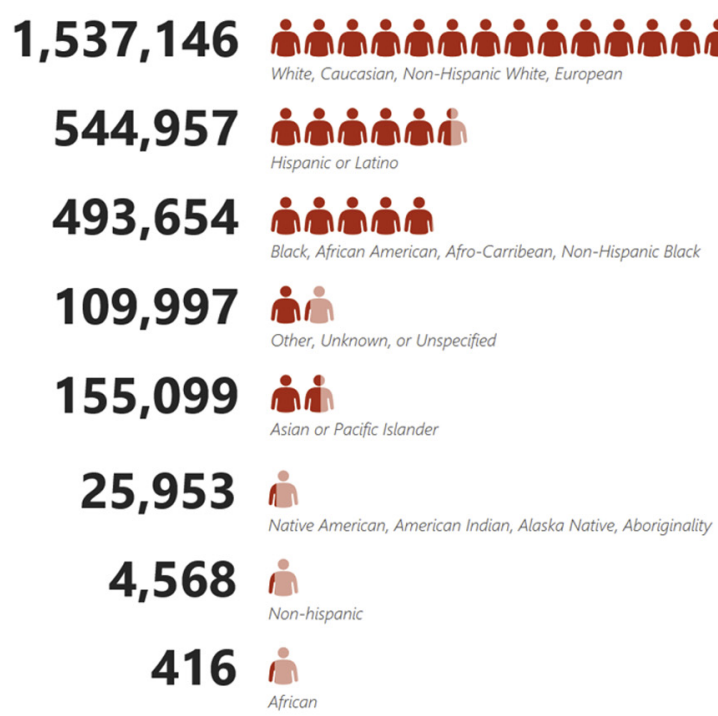

61 Other/Mixed or Other/Multiple

35 i̊

Figure 3. People graph illustrating the total number of women with a history of any hypertensive disorder of pregnancy in included studies by reported race or ethnicity group.

across included studies, and, when authors did report this information, several different terms were used to describe the same construct (eg, Caucasian, white, non-Hispanic white, European descent). Further, we identified only 1 study ${ }^{148}$ whose authors reported classifying participants into a specific ethnic group based on an existing framework or prespecified criteria.

In their 2020 review, Bokor-Billmann et al. ${ }^{35}$ noted that a substantive portion of studies in general medicine, surgery, and oncology published between 2007 and 2018 reported non convenience race or ethnic groupings. Similarly, we found that across included studies, thousands of women with HDP were assigned to a category referred to as other to represent their race. In addition, we noted that only 3 studies ${ }^{64,75,132}$ included in this review reported any category that captured individuals who identify as multiracial. This finding is concerning given that individuals who identifiy as multiracial may experience inequalities in health that are different from those who identify with a single racial group. ${ }^{180}$ In the year 2000, the US Census started distinguishing Asian and Pacific Islander as 2 separate racial categories. ${ }^{81}$ However, the authors of 5 studies, ${ }^{53,64,132,142,171}$ all of which were published in 2016 or later, still reported individuals as belonging to a combined Asian/Pacific Islander race. This finding points to the limitations of using registry and administrative data in epidemiologic studies, as researchers using these types of data cannot control how they are collected and may not be able to adapt their reporting of variables if data collection methods change over time.
Previous reviews ${ }^{15,32,35}$, have noted a gap in the reporting of criteria used to categorize individuals into race and/or ethnic groups in medical research. This finding is likely driven by a lack of consensus in the definition of race and ethnicity and a paucity of standardized classification systems and reporting standards. ${ }^{35}$ It may not be feasible to classify all individuals into specific race or ethnic categories and, in some cases, categories may need to be combined to gain statistical power or to preserve the anonymity of participants. ${ }^{12}$ However, no matter which approach is taken, it is imperative that researchers examining associations between HDP and CVD carefully delineate and define the categories they intend to use and consider the possible heterogeneity that doing so may create, as it could have important implications for the interpretation and meaning of results. ${ }^{11}$

Although previous literature supports the use of race and/ or ethnicity obtained through self-report as the gold standard method of assessment, ${ }^{11,182}$ we observed that only about onethird of authors used self-report as a means to obtain these data. One study ${ }^{85}$ used father's birthplace as a proxy for participant ethnicity, and an additional $25 \%$ reported using existing records (eg, registry and other administrative data) to obtain information about demographic variables with no explicit mention about the potential for misclassification and its potential impact on study findings. An individual's ethnic identity can change depending on the context (so-called situational ethnicity ${ }^{8}$ ) both in terms of how they define themselves and how they may be perceived by society, ${ }^{11,12}$ which underscores the need for participants to self-declare this information. 
Similar to the findings of Ahdieh and Hahn, ${ }^{32}$ we found that most studies statistically controlled for race and/or ethnicity in multivariable models by including them as potential confounders in the association between HDP and CVD. However, in etiologic studies, such as most of those included in this review, race and ethnicity can play an important role in helping researchers understand the effect of HDP on CVD through their interaction with race. ${ }^{183}$ We identified only 2 studies $^{75,122}$ that reported on the use of interaction terms to investigate the statistical significance (and magnitude) of the effect of race and HDP exposure on CVD outcomes. One study ${ }^{75}$ only reported the results of statistically significant interactions, whereas the other ${ }^{122}$ reported on the results of all interactions tested, regardless of statistical significance.

Although significant interaction terms may signal important race and/or ethnic differences in the risk of CVD in women with a history of HDP, a lack of significance should not be interpreted as direct counter evidence of a difference between race and/or ethnic groups. ${ }^{184}$ Tests for interaction are dependent on the type of measurement scale (ie, multiplicative or additive), and researchers can reach different conclusions depending on the scale used. ${ }^{185}$ Further, studies may not be adequately powered to identify significant interactions even if they are present.

If more than just a few studies had made use of reporting guidelines (eg, STROBE) to structure and report on their methodology and findings, we would likely have gained more robust insight into the rationale behind the use of race, ethnicity, and national origin in studies published on this topic. Important questions remain about whether (1) race and ethnicity variables were generally incorporated into models based on a priori conceptual frameworks or (2) decisions about covariate selection were primarily made using statistical approaches and (3) whether researchers chose not to investigate statistical interaction because of a lack of power or whether several more studies tested these types of interactions and simply did not report them because of nonsignificant findings. ${ }^{186}$ Further, a lack of explanation or justification for the methods used by some authors (eg, the use of husband's occupation as a proxy for participant social status, the use of father's birthplace as a proxy for participant ethnicity, and limiting secondary analyses to white participants) could be perceived as gender and racial bias, as they appear to place a higher value on men's status in society as well as individuals of white race. However, without more insight into the rationale for these methods, it is difficult to draw any firm conclusions.

\section{Harnesing the power to perform cardio-obstetrics analyses through an intersectional lens}

If the goal is to attain a more comprehensive understanding of disparities in women's cardiovascular health, future work ${ }^{187-189}$ must move beyond the collection and use of a single or small group of sociodemographic characteristics focused solely on the individual (eg, race and/or ethnicity, age, sex, education) and move toward approaches that account for a more robust range of important social factors. ${ }^{187-189}$ Given that peoples' life circumstances are "often determined at higher levels of social organization," $" 190$ the use of more comprehensive statistical approaches that continue to focus on the use of a single race and/or ethnicity variable as a covariate, mediator, stratification variable, and effect modifier will fail to go far enough. ${ }^{190}$ To this end, it has been suggested that researchers apply an intersectional approach to health research-one that uses a multidimensional lens with the goal of gaining a better understanding of the interactive, indirect, and cumulative effects of multiple determinants of health (eg, interpersonal, sociocultural, and community factors) on disease outcomes. ${ }^{4,5,191,192}$

An intersectional approach to cardio-obstetrics research counters the notion that women are a homogeneous group of individuals - even if categorized as belonging to the same race or ethnic group. ${ }^{193}$ This paradigm emphasizes the need to consider a wider set of social variables in health research and is especially important for women, as there is evidence that both structural and interpersonal discrimination are more prevalent in individuals identifying with this gender compared with men. ${ }^{194}$ For example, being a woman and being black each bring their own set of unique social experiences that can collectively affect risk for $\mathrm{CVD}^{193}$ and $\mathrm{HDP}^{195}$ but in a way that is more than simply the sum of being a woman and being black. Indeed, the use of more sophisticated statistical methods undertaken with the aim of investigating the synergistic effects of individual- and population-level sociodemographic measures (eg, socioeconomic status, immigration status, education, geography, gender identity, and discrimination) ${ }^{10,190}$ can only be considered if researchers have access to robust data on diverse populations.

\section{Strengths and limitations}

We completed a rapid and comprehensive review of the use of race, ethnicity, and national origin in observational studies assessing CVD morbidity and mortality in women with a history of HDP. This work not only builds on existing literature addressing the use of race and ethnicity in medical research but provides new knowledge about the use of these variables within the context of cardiovascular risk in women with a history of HDP. This study, however, is not without limitations. Because this was a rapid review, we streamlined components of the SR process; however, several different measures were taken to balance methodologic rigour and timeliness. Our literature base was mainly built from the included studies of recently published SRs, all of which had major methodologic shortcomings. However, we identified and included 6 SRs, all of which used comprehensive inclusion criteria, and completed a search update to look for more recently published primary studies of potential relevance. As such, although we cannot be certain that all the available literature on this topic was captured, we are satisfied that we have likely captured the most relevant primary studies published on this topic. Further, although data extraction was not completed in duplicate, we pilot tested extraction forms and completed data audits to ensure their accuracy and found very little error or omission. If the country of conduct was not reported, we extracted the geographic location of the corresponding author in its place. We recognize that this may not have been an accurate proxy for participant location; however, this was rarely required, and in each instance, we were able to use additional information (eg, funding and data sources) to 
help triangulate the information. Finally, we only included English-language literature, which may limit the generalizability of our results; however, none of the included SRs that placed no restriction on language of publication included foreign-language studies.

\section{Conclusions and a Call to Action}

Based on our findings, race and ethinicity are not uniformly documented in studies of women with HDP, and, when documentation exists, it is inconsistently applied. Further, despite a high burden of HDP among Hispanic and black women in certain geographic regions (eg, Botswana), existing data disproportionally represents white women in North American and/or northern European settings. These findings highlight significant areas for improvement in HDP research, especially with regard to the need to study more diverse populations, as well as the use of more robust and standardized methods for collecting, reporting, and use of sociodemographic information.

Both short- and long-term changes can be made to facilitate a better understanding of the reasons behind cardiovascular health disparities in women with a history of HDP that are linked to race and ethnicity. At a minimum, cardiovascular researchers should be transparent about the reasons information about race and ethnicity are collected and report the rationale behind their categorization, ${ }^{15}$ which should be built on classification frameworks that are internationally comparable. Furthermore, it is essential that they carefully reflect on the appropriateness of using a standalone race and/or ethnicitiy variable in statistical models and ensure that the interpretation of data obtained from the use of these variables is appropriate.

Ultimately, if disparities in CVD outcomes for women with a history of HDP are to be eliminated, we must seek better ways to identify and study them. This will require the development of (1) international consensus standards for the use and reporting of race and ethnicity in clinical research; (2) standardized data collection tools; (3) the development of large-scale geographically and demographically diverse women's health registries that allow for the collection of a comprehensive set of sociodemographic information about participants, and repeated and long-term follow up; and (4) race- and ethnicity-focused analyses that are designed and carried out using an intersectional approach.

\section{Funding Sources}

No funding was received for this study.

\section{Disclosures}

A.J. is supported by a Doctoral Research Award from the Canadian Institutes of Health Research. V.T. is supported by the University of Ottawa Cardiac Research Endowed Fellowship. T.C. is supported by a Clinician Scientist I Salary Support Award from the Heart and Stroke Foundation of Ontario, and by the Chair Award from the University of Ottawa Heart Institute's Canadian Women's Heart Health Centre. J.E. receives research funding from the Canadian Institutes of Health Research, the Canadian Cardiovascular Society, and Brain Canada and is a Heart and Stroke Foundation of Canada National New Investigator.

\section{References}

1. Jaffer S, Foulds HJA, Parry M, et al. The Canadian Women's Heart Health Alliance ATLAS on the epidemiology, diagnosis, and management of cardiovascular disease in women-chapter 2: scope of the problem. CJC Open 2021;3:1-11.

2. Roth GA, Johnson C, Abajobir A, et al. Global, regional, and national burden of cardiovascular diseases for 10 causes, 1990 to 2015. J Am Coll Cardiol 2017:70:1-25.

3. Ray JG, Vermeulen MJ, Schull MJ, Redelmeier DA. Cardiovascular health after maternal placental syndromes (CHAMPS): populationbased retrospective cohort study. Lancet 2005;366:1797-803.

4. George J, Mathur R, Shah AD, et al. Ethnicity and the first diagnosis of a wide range of cardiovascular diseases: associations in a linked electronic health record cohort of 1 million patients. PLoS ONE 2017;12: e0178945-.

5. Johnson JD, Louis JM. Does race or ethnicity play a role in the origin, pathophysiology, and outcomes of preeclampsia? An expert review of the literature. Am J Obstet Gynecol 2020.

6. Huppertz B. Placental origins of preeclampsia. Hypertension 2008;51: 970-5.

7. Ghulmiyyah L, Sibai B. Maternal mortality from preeclampsia/ eclampsia. Semin Perinatol 2012;36:56-9.

8. Mays VM, Ponce NA, Washington DL, Cochran SD. Classification of race and ethnicity: implications for public health. Annu Rev Public Health 2003;24:83-110.

9. Guyatt G, Cairns J, Churchill D, et al. Evidence-based medicine: a new approach to teaching the practice of medicine. JAMA 1992;268:2420-5.

10. Ioannidis JPA, Powe NR, Yancy C. Recalibrating the use of race in medical research. JAMA 2021;325:623-4.

11. Ross PT, Hart-Johnson T, Santen SA, Zaidi NLB. Considerations for using race and ethnicity as quantitative variables in medical education research. Perspect Med Educ 2020;9:318-23.

12. Lin SS, Kelsey JL. Use of race and ethnicity in epidemiologic research: concepts, methodological issues, and suggestions for research. Epidemiol Rev 2000;22:187-202.

13. Proposed standards for race-based and indigenous identity data collection and health reporting in Canada. Ottawa, ON: Canadian Institute for Health Information, 2020.

14. Muncan B. Cardiovascular disease in racial/ethnic minority populations: illness burden and overview of community-based interventions. Public Health Rev 2018;39:32.

15. Comstock RD, Castillo EM, Lindsay SP. Four-year review of the use of race and ethnicity in epidemiologic and public health research. Am J Epidemiol 2004;159:611-9.

16. Jones CP. Levels of racism: a theoretic framework and a gardener's tale. Am J Public Health 2000;90:1212-5.

17. Be part of a Peoples' Panel to guide how race and ethnicity data are used in health research in Ontario Toronto, ON: IC/ES. Available from: https://www.ices.on.ca/Newsroom/Announcements-and-Events/2021/ Striving-for-community-driven-anti-racist-use-of-race-ethnicity-andimmigration-data.

18. ICES. In: @ICESOntario, editor. We're recruiting Ontarians to be part of a People's Panel to ensure the anti-racist use of race, ethnicity and immigration data Please share widely, https:// surveymonkeycom/r/YW6XHVT @Tamarack_Inst @digitaljustlab:. Twitter 2021. 
19. Flanagin A, Frey T, Christiansen SL, Bauchner $\mathrm{H}$. The reporting of race and ethnicity in medical and science journals: comments invited. JAMA 2021;325:1049-52.

20. Ananth CV, Keyes KM, Wapner RJ. Pre-eclampsia rates in the United States, 1980-2010: age-period-cohort analysis. BMJ 2013;347:f6564.

21. Warrington JP, George EM, Palei AC, Spradley FT, Granger JP. Recent advances in the understanding of the pathophysiology of preeclampsia. Hypertension 2013;62:666-73.

22. Noubiap JJ, Bigna JJ, Nyaga UF, et al. The burden of hypertensive disorders of pregnancy in Africa: a systematic review and meta-analysis. J Clin Hypertens (Greenwich) 2019;21:479-88.

23. Ganann R, Ciliska D, Thomas H. Expediting systematic reviews: methods and implications of rapid reviews. Implement Sci 2010;5:56.

24. Khangura S, Konnyu K, Cushman R, Grimshaw J, Moher D. Evidence summaries: the evolution of a rapid review approach. Syst Rev 2012;1(1):10.

25. Tricco AC, Antony J, Zarin W, et al. A scoping review of rapid review methods. BMC Med 2015;13:224.

26. Polisena J, Garritty C, Kamel C, Stevens A, Abou-Setta AM. Rapid review programs to support health care and policy decision making: a descriptive analysis of processes and methods. Syst Rev 2015;4(1):26.

27. Kaltenthaler E, Cooper K, Pandor A, Martyn-St, James M, Chatters R, Wong R. The use of rapid review methods in health technology assessments: 3 case studies. BMC Med Res Methodol 2016;16:108.

28. Arevalo-Rodriguez I, Steingart KR, Tricco AC, et al. Current methods for development of rapid reviews about diagnostic tests: an international survey. BMC Med Res Methodol 2020;20:115.

29. Pham MT, Waddell L, Rajić A, Sargeant JM, Papadopoulos A, McEwen SA. Implications of applying methodological shortcuts to expedite systematic reviews: three case studies using systematic reviews from agri-food public health. Res Synth Methods 2016;7:433-46.

30. Hamel C, Michaud A, Thuku M, Skidmore B, Stevens A, NussbaumerStreit B, et al. Defining rapid reviews: a systematic scoping review and thematic analysis of definitions and defining characteristics of rapid reviews. J Clin Epidemiol 2021;129:74-85.

31. Watt A, Cameron A, Sturm L, et al. Rapid reviews versus full systematic reviews: an inventory of current methods and practice in health technology assessment. Int J Technol Assess Health Care 2008;24:133-9.

32. Ahdieh L, Hahn RA. Use of the terms 'race', 'ethnicity', and 'national origins': a review of articles in the American Journal of Public Health, 1980-1989. Ethnicity Health 1996;1:95-8.

33. Jones CP, LaVeist TA, Lillie-Blanton M. "Race" in the epidemiologic literature: an examination of the American Journal of Epidemiology, 1921-1990. Am J Epidemiol 1991;134:1079-84.

34. Williams DR. The concept of race in Health Services Research: 1966 to 1990. Health Serv Res 1994;29:261-74.

35. Bokor-Billmann T, Langan EA, Billmann F. The reporting of race and/ or ethnicity in the medical literature: a retrospective bibliometric analysis confirmed room for improvement. J Clin Epidemiol 2020;119:1-6.

36. Whelton PK, Carey RM, Aronow WS, et al. 2017 ACC/AHA/AAPA/ ABC/ACPM/AGS/APhA/ASH/ASPC/NMA/PCNA guideline for the prevention, detection, evaluation, and management of high blood pressure in adults: executive summary: a report of the American College of Cardiology/American Heart Association Task Force on Clinical Practice Guidelines. Hypertension 2018;71:1269-324.
37. Vahedi FA, Gholizadeh L, Heydari M. Hypertensive disorders of pregnancy and risk of future cardiovascular disease in women. Nurs Womens Health 2020;24:91-100.

38. Wu R, Wang T, Gu R, et al. Hypertensive disorders of pregnancy and risk of cardiovascular disease-related morbidity and mortality: a systematic review and meta-analysis. Cardiology 2020;145:633-47.

39. Strings Attached: CADTH's Database Search Filters Ottawa, ON: CADTH. Available from: https://www.cadth.ca/resources/findingevidence/strings-attached-cadths-database-search-filters\#syst.

40. Fraser C, Murray A, Burr J. Identifying observational studies of surgical interventions in MEDLINE and EMBASE. BMC Med Res Methodol 2006;6:41.

41. Elm Ev, Altman DG, Egger M, Pocock SJ, Gøtzsche PC, Vandenbroucke JP. Strengthening the reporting of observational studies in epidemiology (STROBE) statement: guidelines for reporting observational studies. BMJ 2007;335:806.

42. Benchimol EI, Smeeth L, Guttmann A, et al. The reporting of studies conducted using observational routinely-collected health data (RECORD) statement. PLoS Med 2015;12:e1001885.

43. Cuschieri S. The STROBE guidelines. Saudi J Anaesth 2019;13(Suppl 1):S31-4.

44. Shea B, Reeves B, Wells G, et al. AMSTAR 2: a critical appraisal tool for systematic reviews that include randomised or non-randomised studies of healthcare interventions, or both. BMJ 2017;358:j4008.

45. Alonso-Ventura V, Li Y, Pasupuleti V, Roman YM, Hernandez AV, Pérez-López FR. Effects of preeclampsia and eclampsia on maternal metabolic and biochemical outcomes in later life: a systematic review and meta-analysis. Metabolism 2020;102:154012.

46. Giorgione V, Ridder A, Kalafat E, Khalil A, Thilaganathan B. Incidence of postpartum hypertension within 2 years of a pregnancy complicated by pre-eclampsia: a systematic review and meta-analysis. BJOG 2020;128:495-503.

47. Lo CCW, Lo ACQ, Leow SH, et al. Future cardiovascular disease risk for women with gestational hypertension: a systematic review and metaanalysis. J Am Heart Assoc 2020;9:e013991.

48. Veiga ECA, Rocha PRH, Caviola LL, et al. Previous preeclampsia and its association with the future development of cardiovascular diseases: a systematic review and meta-analysis. Clinics (Sao Paulo) 2020;76: e1999.

49. Dall'Asta A, D'Antonio F, Saccone G, et al. Cardiovascular events following pregnancy complicated by pre-eclampsia with emphasis on comparison between early- and late-onset forms: systematic review and meta-analysis. Ultrasound Obstet Gynecol 2021;57:698-709.

50. Andersgaard AB, Acharya G, Mathiesen EB, Johnsen SH, Straume B, Øian P. Recurrence and long-term maternal health risks of hypertensive disorders of pregnancy: a population-based study. Am J Obstet Gynecol 2012;206. 143.e1-8.

51. Andolf EG, Sydsjö GC, Bladh MK, Berg G, Sharma S. Hypertensive disorders in pregnancy and later dementia: a Swedish National Register Study. Acta Obstet Gynecol Scand 2017;96:464-71.

52. Arnadottir GA, Geirsson RT, Arngrimsson R, Jonsdottir LS, Olafsson O. Cardiovascular death in women who had hypertension in pregnancy: a case-control study. BJOG 2005;112(3):286-92.

53. Arnaout R, Nah G, Marcus G, et al. Pregnancy complications and premature cardiovascular events among 1.6 million California pregnancies. Open Heart 2019;6:e000927. 
54. Arnott C, Nelson M, Alfaro Ramirez M, et al. Maternal cardiovascular risk after hypertensive disorder of pregnancy. Heart (British Cardiac Society) 2020;106(24):1927-33.

55. Auger N, Fraser WD, Schnitzer M, Leduc L, Healy-Profitós J, Paradis G. Recurrent pre-eclampsia and subsequent cardiovascular risk. Heart 2017;103:235-43.

56. Aykas F, Solak Y, Erden A, et al. Persistence of cardiovascular risk factors in women with previous preeclampsia: a long-term follow-up study. J Investig Med 2015;63:641-5.

57. Behrens I, Basit S, Lykke JA, et al. Association between hypertensive disorders of pregnancy and later risk of cardiomyopathy. JAMA 2016;315:1026-33.

58. Behrens I, Basit S, Lykke JA, et al. Hypertensive disorders of pregnancy and peripartum cardiomyopathy: A nationwide cohort study. PLoS ONE 2019;14(2):e0211857.

59. Behrens I, Basit S, Melbye M, et al. Risk of post-pregnancy hypertension in women with a history of hypertensive disorders of pregnancy: nationwide cohort study. BMJ 2017;358:j3078.

60. Berends AL, de Groot CJ, Sijbrands EJ, et al. Shared constitutional risks for maternal vascular-related pregnancy complications and future cardiovascular disease. Hypertension 2008;51(4):1034-41.

61. Bergen NE, Schalekamp-Timmermans S, Roos-Hesselink J, Roeters van Lennep JE, Jaddoe VVW, Steegers EAP. Hypertensive disorders of pregnancy and subsequent maternal cardiovascular health. Eur J Epidemiol 2018;33:763-71.

62. Best LG, Lunday L, Webster E, Falcon GR, Beal JR. Pre-eclampsia and risk of subsequent hypertension: in an American Indian population. Hypertens Pregnancy 2017;36:131-7.

63. Bhattacharya S, Prescott GJ, Iversen L, Campbell DM, Smith WC, Hannaford PC. Hypertensive disorders of pregnancy and future health and mortality: a record linkage study. Pregnancy Hypertens 2012;2(1): $1-7$.

64. Black MH, Zhou H, Sacks DA, Dublin S, Lawrence JM, Harrison TN, et al. Hypertensive disorders first identified in pregnancy increase risk for incident prehypertension and hypertension in the year after delivery. J Hypertens 2016;34:728-35.

65. Bokslag A, Teunissen PW, Franssen C, et al. Effect of early-onset preeclampsia on cardiovascular risk in the fifth decade of life. Am J Obstet Gynecol 2017;216. 523.e1-.e7.

66. Borna S, Neamatipoor E, Radman N. Risk of coronary artery disease in women with history of pregnancies complicated by preeclampsia and LBW. J Matern Fetal Neonatal Med 2012;25:1114-6.

67. Breetveld N, Ghossein-Doha C, van Kuijk S, et al. Cardiovascular disease risk is only elevated in hypertensive, formerly preeclamptic women. BJOG 2015;122:1092-100.

68. Brown DW, Dueker N, Jamieson DJ, et al. Preeclampsia and the risk of ischemic stroke among young women: results from the Stroke Prevention in Young Women Study. Stroke 2006;37:1055-9.

69. Cain MA, Salemi JL, Tanner JP, Kirby RS, Salihu HM, Louis JM. Pregnancy as a window to future health: maternal placental syndromes and short-term cardiovascular outcomes. Am J Obstet Gynecol 2016;215(4). 484.e1-.e14.

70. Callaway LK, David McIntyre H, Williams GM, Najman JM, Lawlor DA, Mamun A. Diagnosis and treatment of hypertension 21 years after a hypertensive disorder of pregnancy. Aust N Z J Obstet Gynaecol 2011;51:437-40.
71. Canoy D, Cairns BJ, Balkwill A, et al. Hypertension in pregnancy and risk of coronary heart disease and stroke: a prospective study in a large UK cohort. Int J Cardiol 2016;222:1012-8.

72. Canti IC, Komlós M, Martins-Costa SH, Ramos JG, Capp E, Corleta H. Risk factors for cardiovascular disease ten years after preeclampsia. Sao Paulo Med J 2010;128:10-3.

73. Carleton H, Forsythe A, Flores R. Remote prognosis of preeclampsia in women 25 years old and younger. Am J Obstet Gynelcol 1988;159: 156-60.

74. Christensen M, Kronborg CS, Eldrup N, Rossen NB, Knudsen UB. Preeclampsia and cardiovascular disease risk assessment-do arterial stiffness and atherosclerosis uncover increased risk ten years after delivery? Pregnancy Hypertens 2016;6:110-4.

75. Cirillo PM, Cohn BA. Pregnancy complications and cardiovascular disease death: 50-year follow-up of the Child Health and Development Studies pregnancy cohort. Circulation 2015;132:1234-42.

76. Dantas EM, Pereira FV, Queiroz JW, et al. Preeclampsia is associated with increased maternal body weight in a northeastern Brazilian population. BMC Pregnancy Childbirth 2013;13:159.

77. de Havenon A, Delic A, Stulberg E, et al. Association of preeclampsia with incident stroke in later life among women in the Framingham Heart Study. JAMA Network Open 2021;4:e215077.

78. Diehl CL, Brost BC, Hogan MC, et al. Preeclampsia as a risk factor for cardiovascular disease later in life: validation of a preeclampsia questionnaire. Am J Obstet Gynecol 2008;198:e11-3.

79. Ditisheim A, Wuerzner G, Ponte B, et al. Prevalence of hypertensive phenotypes after preeclampsia: a prospective cohort study. Hypertension 2018;71:103-9.

80. Drost JT, Arpaci G, Ottervanger JP, et al. Cardiovascular risk factors in women 10 years post early preeclampsia: the Preeclampsia Risk EValuation in FEMales study (PREVFEM). Eur J Prev Cardiol 2012;19: $1138-44$

81. Edlow AG, Srinivas SK, Elovitz MA. Investigating the risk of hypertension shortly after pregnancies complicated by preeclampsia. Am J Obstet Gynecol 2009;200:e60-2.

82. Egeland GM, Skurtveit S, Staff AC, et al. Pregnancy-related risk factors are associated with a significant burden of treated hypertension within 10 years of delivery: findings from a population-based Norwegian cohort. J Am Heart Assoc 2018;7:e008318.

83. Ehrenthal DB, Goldstein ND, Wu P, Rogers S, Townsend RR, Edwards DG. Arterial stiffness and wave reflection 1 year after a pregnancy complicated by hypertension. J Clin Hypertens (Greenwich) 2014;16:695-9.

84. Forest JC, Girouard J, Massé J, et al. Early occurrence of metabolic syndrome after hypertension in pregnancy. Obstet Gynecol 2005;105: 1373-80.

85. Funai EF, Friedlander Y, Paltiel O, et al. Long-term mortality after preeclampsia. Epidemiology 2005;16:206-15.

86. Garovic VD, Bailey KR, Boerwinkle E, et al. Hypertension in pregnancy as a risk factor for cardiovascular disease later in life. J Hypertens 2010;28:826-33.

87. Garovic VD, White WM, Vaughan L, et al. Incidence and long-term outcomes of hypertensive disorders of pregnancy. J Am Col Cardiol 2020;75:2323-34. 
88. Gastrich MD, Zinonos S, Bachmann G, et al. Preeclamptic women are at significantly higher risk of future cardiovascular outcomes over a 15 year period. J Womens Health (Larchmt) 2019;29:74-83.

89. Gaugler-Senden IP, Berends AL, de Groot CJ, Steegers EA. Severe, very early onset preeclampsia: subsequent pregnancies and future parental cardiovascular health. Eur J Obstet Gynecol Reprod Biol 2008;140: $171-7$.

90. Ghossein-Doha C, van Neer J, Wissink B, et al. Pre-eclampsia: an important risk factor for asymptomatic heart failure. Ultrasound Obstet Gynecol 2017;49:143-9.

91. Grandi SM, Reynier P, Platt RW, Basso O, Filion KB. The timing of onset of hypertensive disorders in pregnancy and the risk of incident hypertension and cardiovascular disease. Int J Cardiol 2018;270:273-5.

92. Grandi SM, Vallée-Pouliot K, Reynier P, et al. Hypertensive disorders in pregnancy and the risk of subsequent cardiovascular disease. Paediatr Perinat Epidemiol 2017;31:412-21.

93. Haas DM, Parker CB, Marsh DJ, Grobman WA, et al. Association of adverse pregnancy outcomes with hypertension 2 to 7 years postpartum. J Am Heart Assoc 2019;8(19):e013092.

94. Hannaford P, Ferry S, Hirsch S. Cardiovascular sequelae of toxaemia of pregnancy. Heart 1997;77:154-8.

95. Haug EB, Horn J, Markovitz AR, et al. Association of conventional cardiovascular risk factors with cardiovascular disease after hypertensive disorders of pregnancy: analysis of the Nord-Trøndelag Health Study. JAMA Cardiol 2019;4:628-35.

96. Haukkamaa L, Salminen M, Laivuori H, Leinonen H, Hiilesmaa V, Kaaja R. Risk for subsequent coronary artery disease after preeclampsia. Am J Cardiol 2004;93:805-8.

97. Hauspurg A, Countouris ME, Jeyabalan A, et al. Risk of hypertension and abnormal biomarkers in the first year postpartum associated with hypertensive disorders of pregnancy among overweight and obese women. Pregnancy Hypertens 2019;15:1-6.

98. Heida KY, Franx A, van Rijn BB, et al. Earlier age of onset of chronic hypertension and type 2 diabetes mellitus after a hypertensive disorder of pregnancy or gestational diabetes mellitus. Hypertension 2015;66: $1116-22$.

99. Hermes W, Franx A, van Pampus MG, et al. Cardiovascular risk factors in women who had hypertensive disorders late in pregnancy: a cohort study. Am J Obstet Gynecol 2013;208. 474.e1-8.

100. Honigberg MC, Riise HKR, Daltveit AK, et al. Heart failure in women with hypertensive disorders of pregnancy: insights from the Cardiovascular Disease in Norway Project. Hypertension (Dallas, Tex:1979) 2020;76(5):1506-13.

101. Honigberg MC, Zekavat SM, Aragam K, et al. Long-term cardiovascular risk in women with hypertension during pregnancy. J Am Coll Cardiol 2019;74:2743-54

102. Hovsepian DA, Sriram N, Kamel H, Fink ME, Navi BB. Acute cerebrovascular disease occurring after hospital discharge for labor and delivery. Stroke 2014;45:1947-50.

103. Huang C-C, Huang C-C, Lin S-Y, et al. Association between hypertensive pregnancy disorders and future risk of stroke in Taiwan: a Nationwide population-based retrospective case-control study. BMC Pregnancy and Childbirth 2020;20:217

104. Irgens HU, Reisaeter L, Irgens LM, Lie RT. Long term mortality of mothers and fathers after pre-eclampsia: population based cohort study. BMJ 2001;323(7323):1213-7.
105. Jónsdóttir LS, Arngrímsson R, Geirsson RT, Sigvaldason H, Sigfússon N. Death rates from ischemic heart disease in women with a history of hypertension in pregnancy. Acta Obstet Gynecol Scand 1995;74:772-6.

106. Kaaja R, Kinnunen T, Luoto R. Regional differences in the prevalence of pre-eclampsia in relation to the risk factors for coronary artery disease in women in Finland. Eur Heart J 2005;26:44-50.

107. Karjalainen L, Tikkanen M, Rantanen K, et al. Stroke in pregnancy and puerperium: validated incidence trends with risk factor analysis in Finland 1987-2016. Neurology 2021;96:e2564-75.

108. Keepanasseril A, Thilaganathan B, Velmurugan B, Kar SS, Maurya DK, Pillai AA. Influence of maternal and perinatal characteristics on risk of postpartum chronic hypertension after pre-eclampsia. Int J Gynaecol Obstet 2020;151:128-33.

109. Kessous R, Shoham-Vardi I, Pariente G, Sergienko R, Sheiner E. Longterm maternal atherosclerotic morbidity in women with pre-eclampsia. Heart 2015;101:442-6.

110. Kestenbaum B, Seliger SL, Easterling TR, et al. Cardiovascular and thromboembolic events following hypertensive pregnancy. Am J Kidney Dis 2003;42:982-9.

111. Kharazmi E, Kaaja R, Fallah M, Luoto R. Pregnancy-related factors and the risk of isolated systolic hypertension. Blood Press 2007;16:50-5.

112. Kumar NR, Grobman WA, Barry O, Clement AC, Lancki N, Yee LM. Evaluating the maternal and perinatal sequelae of severe gestational hypertension. Am J Obstet Gynelcol MFM 2021;3:100280.

113. Kuo YL, Chan TF, Wu CY, Ker CR, Tu HP. Preeclampsia-eclampsia and future cardiovascular risk among women in Taiwan. Taiwan J Obstet Gynecol 2018;57:364-9.

114. Kurabayashi T, Mizunuma H, Kubota T, Kiyohara Y, Nagai K, Hayashi K. Pregnancy-induced hypertension is associated with maternal history and a risk of cardiovascular disease in later life: Japanese crosssectional study. Maturitas 2013;75:227-31.

115. Langlois AWR, Park AL, Lentz EJM, Ray JG. Preeclampsia brings the risk of premature cardiovascular disease in women closer to that of men. Can J Cardiol 2020;36:60-8.

116. Leon LJ, McCarthy FP, Direk K, et al. Preeclampsia and cardiovascular disease in a large UK pregnancy cohort of linked electronic health records: a CALIBER study. Circulation 2019;140(13):1050-60.

117. Lin YS, Tang CH, Yang CY, et al. Effect of pre-eclampsia-eclampsia on major cardiovascular events among peripartum women in Taiwan. Am J Cardiol 2011;107:325-30

118. Lisonkova S, Razaz N, Sabr Y, et al. Maternal risk factors and adverse birth outcomes associated with HELLP syndrome: a population-based study. BJOG 2020;127:1189-98.

119. Luoto R, Kharazmi E, Whitley E, Raitanen J, Gissler M, Hemminki E. Systolic hypertension in pregnancy and cardiovascular mortality: a 44year follow-up study. Hypertens Pregnancy 2008;27:87-94.

120. Lykke JA, Langhoff-Roos J, Lockwood CJ, Triche EW, Paidas MJ. Mortality of mothers from cardiovascular and non-cardiovascular causes following pregnancy complications in first delivery. Paediatr Perinat Epidemiol 2010;24:323-30.

121. Lykke JA, Langhoff-Roos J, Sibai BM, Funai EF, Triche EW, Paidas MJ. Hypertensive pregnancy disorders and subsequent cardiovascular morbidity and type 2 diabetes mellitus in the mother. Hypertension 2009;53:944-51. 
122. Malek AM, Wilson DA, Turan TN, Mateus J, Lackland DT, Hunt KJ. Maternal coronary heart disease, stroke, and mortality within 1,3, and 5 years of delivery among women with hypertensive disorders of pregnancy and pre-pregnancy hypertension. J Am Heart Assoc 2021;10: e018155.

123. Mangos GJ, Spaan JJ, Pirabhahar S, Brown MA. Markers of cardiovascular disease risk after hypertension in pregnancy. J Hypertens 2012;30:351-8.

124. Mann JI, Doll R, Thorogood M, Vessey MP, Waters WE. Risk factors for myocardial infarction in young women. Br J Prev Soc Med 1976;30: 94-100.

125. Männistö T, Mendola P, Vääräsmäki M, et al. Elevated blood pressure in pregnancy and subsequent chronic disease risk. Circulation 2013;127:681-90.

126. Manten GT, Sikkema MJ, Voorbij HA, Visser GH, Bruinse HW, Franx A. Risk factors for cardiovascular disease in women with a history of pregnancy complicated by preeclampsia or intrauterine growth restriction. Hypertens Pregnancy 2007;26:39-50.

127. Marín R, Gorostidi M, Portal CG, Sánchez M, Sánchez E, Alvarez J. Long-term prognosis of hypertension in pregnancy. Hypertens Pregnancy 2000;19:199-209.

128. Markovitz AR, Stuart JJ, Horn J, et al. Does pregnancy complication history improve cardiovascular disease risk prediction? Findings from the HUNT study in Norway. Eur Heart J 2019;40:1113-20.

129. McDonald EG, Dayan N, Pelletier R, Eisenberg MJ, Pilote L. Premature cardiovascular disease following a history of hypertensive disorder of pregnancy. Int J Cardiol 2016;219:9-13.

130. McDonald SD, Ray J, Teo K, et al. Measures of cardiovascular risk and subclinical atherosclerosis in a cohort of women with a remote history of preeclampsia. Atherosclerosis 2013;229:234-9.

131. Melchiorre K, Sutherland GR, Liberati M, Thilaganathan B. Preeclampsia is associated with persistent postpartum cardiovascular impairment. Hypertension 2011;58(4):709-15.

132. Miller EC, Boehme AK, Chung NT, et al. Aspirin reduces long-term stroke risk in women with prior hypertensive disorders of pregnancy. Neurology 2019;92:e305-16.

133. Mito A, Arata N, Qiu D, et al. Hypertensive disorders of pregnancy: a strong risk factor for subsequent hypertension 5 years after delivery. Hypertens Res 2018;41:141-6.

134. Moe K, Sugulle M, Dechend R, Staff AC. Risk prediction of maternal cardiovascular disease one year after hypertensive pregnancy complications or gestational diabetes mellitus. Eur J Prev Cardiol 2020;27: 1273-83.

135. Mongraw-Chaffin ML, Cirillo PM, Cohn BA. Preeclampsia and cardiovascular disease death: prospective evidence from the child health and development studies cohort. Hypertension 2010;56:166-71.

136. Nelander M, Cnattingius S, Åkerud H, Wikström J, Pedersen NL, Wikström AK. Pregnancy hypertensive disease and risk of dementia and cardiovascular disease in women aged 65 years or older: a cohort study. BMJ Open 2016;6:e009880.

137. Nohira T. Hypertension and metabolic abnormalities later in life after preeclampsia. Hypertens Res Pregnancy 2013;1:52-6.

138. Osoti AO, Page ST, Richardson BA, et al. Postpartum metabolic syndrome after gestational hypertension and preeclampsia, a prospective cohort study. Pregnancy Hypertens 2019;18:35-41.
139. Parikh NI, Norberg M, Ingelsson E, et al. Association of pregnancy complications and characteristics with future risk of elevated blood pressure. Hypertension 2017;69:475-83.

140. Park Y, Cho GJ, Kim LY, Lee TS, Oh MJ, Kim YH. Preeclampsia increases the incidence of postpartum cerebrovascular disease in korean population. J Korean Med Sci 2018;33:e35.

141. Quesada O, Park K, Wei J, et al. Left ventricular mass and myocardial scarring in women with hypertensive disorders of pregnancy. Open Heart 2020;7:e001273.

142. Redman EK, Hauspurg A, Hubel CA, Roberts JM, Jeyabalan A. Clinical course, associated factors, and blood pressure profile of delayedonset postpartum preeclampsia. Obstet Gynecol 2019;134:995-1001.

143. Riise HK, Sulo G, Tell GS, et al. Incident coronary heart disease after preeclampsia: role of reduced fetal growth, preterm delivery, and parity. J Am Heart Assoc 2017;6:e004158.

144. Riise HKR, Sulo G, Tell GS, et al. Hypertensive pregnancy disorders increase the risk of maternal cardiovascular disease after adjustment for cardiovascular risk factors. Int J Cardiol 2019;282:81-7.

145. Riise HKR, Sulo G, Tell GS, et al. Association between gestational hypertension and risk of cardiovascular disease among 617589 Norwegian women. J Am Heart Assoc 2018;7:e008337.

146. Rosenberg L, Miller DR, Kaufman DW, et al. Myocardial infarction in women under 50 years of age. JAMA 1983;250:2801-6.

147. Savitz DA, Danilack VA, Elston B, Lipkind HS. Pregnancy-induced hypertension and diabetes and the risk of cardiovascular disease, stroke, and diabetes hospitalization in the year following delivery. Am J Epidemiol 2014;180:41-4.

148. Schokker SA, Van Oostwaard MF, Melman EM, et al. Cerebrovascular, cardiovascular and renal hypertensive disease after hypertensive disorders of pregnancy. Pregnancy Hypertens 2015;5:287-93.

149. Shahbazian N, Shahbazian H, Ehsanpour A, Aref A, Gharibzadeh S. Hypertension and microalbuminuria 5 years after pregnancies complicated by pre-eclampsia. Iran J Kidney Dis 2011;5:324-7.

150. Shalom G, Shoham-Vardi I, Sergienko R, Wiznitzer A, Sherf M, Sheiner E. Is preeclampsia a significant risk factor for long-term hospitalizations and morbidity? J Matern Fetal Neonatal Med 2013;26: $13-5$.

151. Sia WW, Pertman SM, Yan RM, Tsuyuki RT. Are preeclampsia and adverse obstetrical outcomes predictors of cardiovascular disease? A casecontrol study of women with heart disease. J Obstet Gynaecol Can 2019;41:1760-7.

152. Skjaerven R, Wilcox AJ, Klungsøyr K, et al. Cardiovascular mortality after pre-eclampsia in one child mothers: prospective, population based cohort study. BMJ 2012;345:e7677.

153. Smith GC, Pell JP, Walsh D. Pregnancy complications and maternal risk of ischaemic heart disease: a retrospective cohort study of 129,290 births. Lancet 2001;357:2002-6.

154. Smith GN, Pudwell J, Saade GR. Impact of the New American Hypertension Guidelines on the prevalence of postpartum hypertension. Am J Perinatol 2019;36:440-2.

155. Spaan JJ, Ekhart T, Spaanderman MEA, Peeters LLH. Remote hemodynamics and renal function in formerly preeclamptic women. Obstet Gynecol 2009;113:853-9.

156. Srinivas SK, Sammel MD, Bastek J, et al. Evaluating the association between all components of the metabolic syndrome and pre-eclampsia. J Matern Fetal Neonatal Med 2009;22:501-9. 
157. Stuart JJ, Tanz LJ, Missmer SA, et al. Hypertensive disorders of pregnancy and maternal cardiovascular disease risk factor development: an observational cohort study. Ann Intern Med 2018;169:224-32.

158. Tang CH, Wu CS, Lee TH, et al. Preeclampsia-eclampsia and the risk of stroke among peripartum in Taiwan. Stroke 2009;40:1162-8.

159. Theilen LH, Fraser A, Hollingshaus MS, et al. All-cause and causespecific mortality after hypertensive disease of pregnancy. Obstet Gynecol 2016;128:238-44.

160. Theilen LH, Meeks H, Fraser A, Esplin MS, Smith KR, Varner MW. Long-term mortality risk and life expectancy following recurrent hypertensive disease of pregnancy. Am J Obstet Gynecol 2018;219. 107.e1-.e6.

161. Thorogood M, Mann J, Murphy M, Vessey M. Fatal stroke and use of oral contraceptives: findings from a case-control study. Am J Epidemiol 1992;136:35-45.

162. Tooher J, Thornton C, Makris A, Ogle R, Korda A, Hennessy A. All hypertensive disorders of pregnancy increase the risk of future cardiovascular disease. Hypertension 2017;70:798-803.

163. Tooher J, Thornton C, Makris A, et al. Hypertension in pregnancy and long-term cardiovascular mortality: a retrospective cohort study. Am J Obstet Gynecol 2016;214. 722.e1-6.

164. Valdés G, Quezada F, Marchant E, et al. Association of remote hypertension in pregnancy with coronary artery disease: a case-control study. Hypertension 2009;53:733-8.

165. Veerbeek JH, Hermes W, Breimer AY, et al. Cardiovascular disease risk factors after early-onset preeclampsia, late-onset preeclampsia, and pregnancy-induced hypertension. Hypertension 2015;65:600-6.

166. Wen J, Shuai W, Ding T, Feng Y, Zhang J, Wang S. Reproductive risk factors for angiographic obstructive coronary artery disease among postmenopausal women. Menopause (New York, NY) 2020;27:1403-10.

167. Wichmann JL, Takx RAP, Nunez JH, et al. Relationship between pregnancy complications and subsequent coronary artery disease assessed by coronary computed tomographic angiography in black women. Circ Cardiovasc Imag 2019;12:e008754.

168. Wikström AK, Haglund B, Olovsson M, Lindeberg SN. The risk of maternal ischaemic heart disease after gestational hypertensive disease. BJOG 2005;112:1486-91.

169. Wilson BJ, Watson MS, Prescott GJ, et al. Hypertensive diseases of pregnancy and risk of hypertension and stroke in later life: results from cohort study. BMJ 2003;326:845.

170. Wu M-Y, Hu P-J, Wong C-S, et al. Long-term clinical outcome of major adverse vascular events after hypertensive disorders of pregnancy. Obstet Gynecol 2021;137:285-93.

171. Wu P, Chew-Graham CA, Maas AH, et al. temporal changes in hypertensive disorders of pregnancy and impact on cardiovascular and obstetric outcomes. AM J Cardiol 2020;125:1508-16.

172. Yeh JS, Cheng HM, Hsu PF, et al. Synergistic effect of gestational hypertension and postpartum incident hypertension on cardiovascular health: a nationwide population study. J Am Heart Assoc 2014;3:e001008.

173. Singh GK, Siahpush M, Liu L, Allender M. racial/ethnic, nativity, and sociodemographic disparities in maternal hypertension in the United States, 2014-2015. Int J Hypertens 2018;2018:7897189.

174. Johnson KM, Zash R, Haviland MJ, et al. Hypertensive disease in pregnancy in Botswana: prevalence and impact on perinatal outcomes. Pregnancy Hypertension 2016;6:418-22.
175. Guerrero S, López-Cortés A, Indacochea A, et al. Analysis of racial/ ethnic representation in select basic and applied cancer research studies. Sci Rep 2018;8:13978.

176. Braun L, Wolfgang M, Dickersin K. Defining race/ethnicity and explaining difference in research studies on lung function. Eur Resp J 2013;41:1362.

177. Nazha B, Mishra M, Pentz R, Owonikoko TK. Enrollment of racial minorities in clinical trials: old problem assumes new urgency in the age of immunotherapy. Am Soc Clin Oncol Educ Book 2019:3-10.

178. Berkowitz ST, Groth SL, Gangaputra S, Patel S. Racial/ethnic disparities in ophthalmology clinical trials resulting in US Food and Drug Administration drug approvals from 2000 to 2020. JAMA Ophthalmol 2021;139:629-37.

179. Valdiviezo C, Garovic VD, Ouyang P. Preeclampsia and hypertensive disease in pregnancy: their contributions to cardiovascular risk. Clin Cardiol 2012;35:160-5.

180. Veenstra G. Black, white, black and white: mixed race and health in Canada. Ethnicity Health 2019;24:113-24.

181. Zavala VA, Bracci PM, Carethers JM, et al. Cancer health disparities in racial/ethnic minorities in the United States. Br J Cancer 2021;124: 315-32.

182. Rothman K, Greenland S, Lash T. Modern Epidemiology. 3rd Edition. Lippincott Williams \& Wilkins, 2008.

183. Holland PW. The false linking of race and causality: lessons from standardized testing. Race and Society 2001;4:219-33.

184. Ward JB, Gartner DR, Keyes KM, Fliss MD, McClure ES, Robinson WR. How do we assess a racial disparity in health? Distribution, interaction, and interpretation in epidemiological studies. Ann Epidemiol 2019;29:1-7.

185. Institute of Medicine (US) Committee on Assessing Interactions Among Social B, and Genetic Factors in Health. Study design and analysis for assessment of interactions. In: Hernandez L, Blazer D, eds. Genes, Behavior, and the Social Environment: Moving Beyond the Nature/Nurture Debate. Washington (DC): National Academies Press (US), 2006.

186. Metelli S, Chaimani A. Challenges in meta-analyses with observational studies. Evid Based Ment Health 2020;23:83.

187. Hankivsky O, Reid C, Cormier R, et al. Exploring the promises of intersectionality for advancing women's health research. Int J Equity Health 2010;9:5.

188. Hankivsky O, Doyal L, Einstein G, et al. The odd couple: using biomedical and intersectional approaches to address health inequities. Glob Health Action 2017;10(sup2):1326686.

189. Allana S, Ski CF, Thompson DR, Clark AM. Intersectionality and heart failure: what clinicians and researchers should know and do. Curr Opin Support Palliat Care 2021;15:141-6.

190. Cooper RS. Social inequality, ethnicity and cardiovascular disease. Int J Epidemiol 2001;30(suppl_1). S48-S.

191. Cooper LA, Ortega AN, Ammerman AS, et al. Calling for a bold new vision of health disparities intervention research. Am J Public Health 2015;105:S374-6.

192. VanderWeele TJ, Robinson WR. On the causal interpretation of race in regressions adjusting for confounding and mediating variables. Epidemiology (Cambridge, Mass) 2014;25:473-84. 
193. Kanchi R, Perlman SE, Chernov C, et al. Gender and race disparities in cardiovascular disease risk factors among New York City adults: New York City Health and Nutrition Examination Survey (NYC HANES) 2013-2014. J Urban Health 2018;95: 801-12.

194. Bey GS, Jesdale B, Forrester S, Person SD, Kiefe C. Intersectional effects of racial and gender discrimination on cardiovascular health vary among black and white women and men in the CARDIA study. SSM Popul Health 2019;8:100446.
195. Ghosh G, Grewal J, Männistö T, et al. Racial/ethnic differences in pregnancy-related hypertensive disease in nulliparous women. Ethn Dis 2014;24:283-9.

\section{Supplementary Material}

To access the supplementary material accompanying this article, visit CJC Open at https://www.cjcopen.ca/ and at https://doi.org/10.1016/j.cjco.2021.08.002. 